Supporting Information

\title{
Scalable Wolff-Kishner Reductions in Extreme Process Windows Using a Silicon Carbide Flow Reactor
}

\author{
Desiree Znidar, ${ }^{\dagger} \ddagger$ Anne O’Kearney-McMullan, ${ }^{\S}$ Rachel Munday, ${ }^{\S}$ Charlotte \\ Wiles, ${ }^{\#}$ Peter Poechlauer, ${ }^{\perp}$ Christoph Schmoelzer, ${ }^{\perp}$ Doris Dallinger*t,, and C. \\ Oliver Kappe ${ }^{*, \dagger}, \dot{+}$
}

${ }^{\dagger}$ Center for Continuous Flow Synthesis and Processing (CC FLOW), Research Center Pharmaceutical Engineering GmbH (RCPE), Inffeldgasse 13, 8010 Graz, Austria

${ }^{\ddagger}$ Institute of Chemistry, University of Graz, NAWI Graz, Heinrichstrasse 28, 8010 Graz, Austria

$\S$ AstraZeneca, Silk Road Business Park, Macclesfield SK10 2NA, United Kingdom \# Chemtrix BV, Galvaniweg 8A, 6101 XH Echt, The Netherlands ${ }^{\perp}$ Patheon Austria GmbH \& Co KG, Sankt-Peter-Straße 25, 4020 Linz, Austria

* Corresponding authors. E-mail: do.dallinger@uni-graz.at, E-mail: oliver.kappe@uni-graz.at

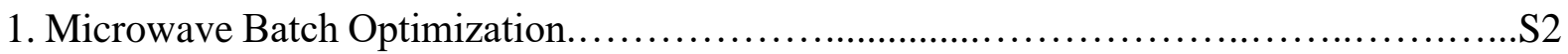

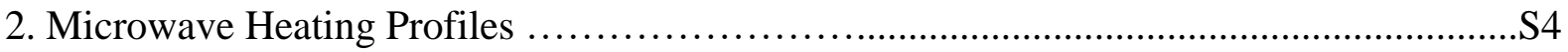

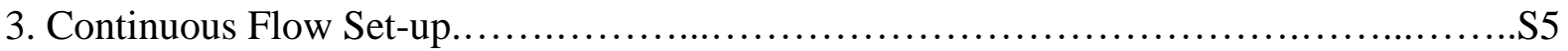

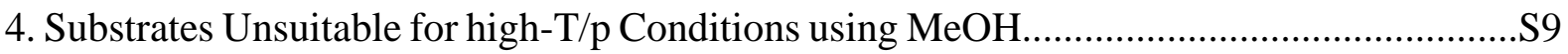

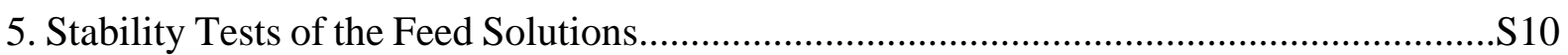

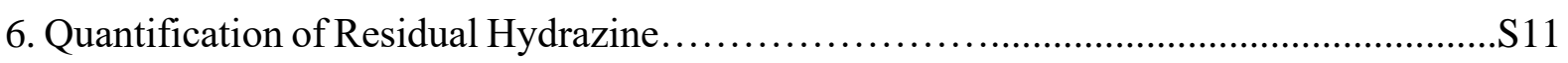

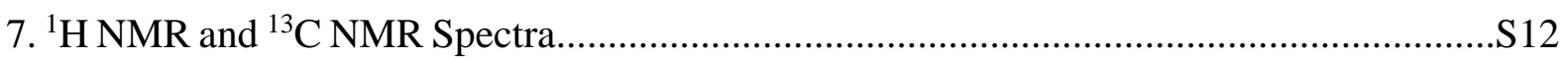




\section{Microwave Batch Optimization}

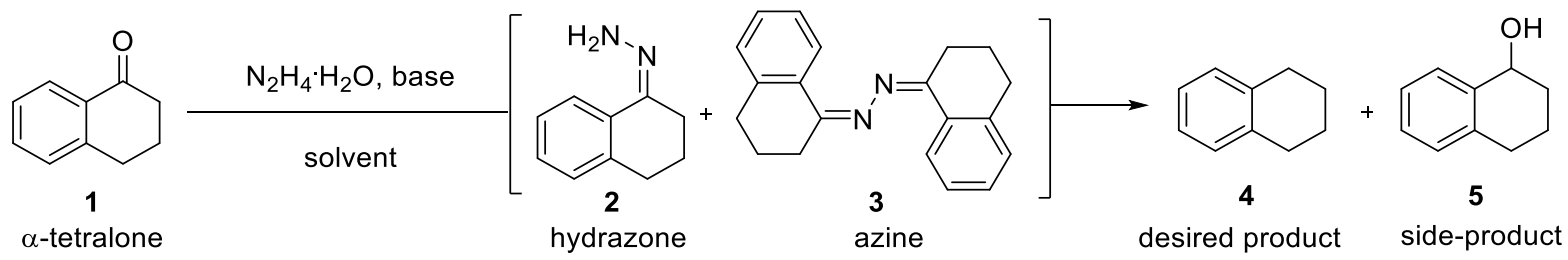

Table S1. Solvent Screening ${ }^{\mathrm{a}}$

\begin{tabular}{cccccccc}
\hline entry & solvent & homogeneity & $\begin{array}{c}\text { bp } \\
{\left[{ }^{\circ} \mathbf{C}\right]}\end{array}$ & $\begin{array}{c}\text { product 4 } \\
{[\%]^{\mathbf{b}}}\end{array}$ & $\begin{array}{c}\mathbf{1 + 2} \\
{[\%]^{\mathbf{b}}}\end{array}$ & $\begin{array}{c}\text { azine 3 } \\
{[\mathbf{\%}]^{\mathbf{b}}}\end{array}$ & $\begin{array}{c}\text { alcohol 5 } \\
{[\%]^{\mathbf{b}}}\end{array}$ \\
\hline 1 & $\mathrm{MeOH}$ & $\checkmark$ & 65 & 53 & 27 & 18 & 2 \\
2 & $\mathrm{EtOH}$ & $\mathbf{X}$ & 78 & 32 & 31 & 18 & 19 \\
3 & $i \mathrm{PrOH}$ & $\mathbf{X}$ & 83 & 24 & 31 & 12 & 33 \\
4 & $t \mathrm{BuOH}$ & $\mathbf{X}$ & 83 & 22 & 39 & 38 & $<1$ \\
5 & $n \mathrm{BuOH}$ & $\mathbf{X}$ & 118 & 42 & 26 & 19 & 13 \\
\hline 6 & $\mathrm{THF}$ & $\mathbf{X}$ & 66 & $<1$ & 51 & 49 & $<1$ \\
7 & Toluene & $\mathbf{X}$ & 111 & $<1$ & 83 & 17 & $<1$ \\
\hline 8 & $\mathrm{EG}$ & $\checkmark$ & 197 & 17 & 83 & $<1$ & $<1$ \\
9 & $\mathrm{DEG}$ & $\checkmark$ & 202 & 33 & 49 & 16 & 2 \\
$10^{\mathrm{c}}$ & $\mathrm{Carbitol}$ & $\checkmark$ & 245 & 67 & 6 & 5 & 5 \\
\hline
\end{tabular}

${ }^{\text {a }}$ Conditions: $0.6 \mathrm{M} \alpha$-tetralone (1), 1.5 equiv $\mathrm{N}_{2} \mathrm{H}_{4} \cdot \mathrm{H}_{2} \mathrm{O}, 3$ equiv $\mathrm{KOH}, 2 \mathrm{~mL}$ solvent, $30 \mathrm{~min}$ at $170{ }^{\circ} \mathrm{C}$, IR temperature measurement, $10 \mathrm{~mL}$ Pyrex vial

${ }^{\mathrm{b}}$ Determined by HPLC peak area integration at $215 \mathrm{~nm}$

${ }^{\mathrm{c}}$ Additional $17 \%$ of an unidentified impurity detected

Table S2. Base Screening ${ }^{\mathrm{a}}$

\begin{tabular}{ccccccc}
\hline entry & base & $\begin{array}{c}\text { T } \\
{\left[{ }^{\circ} \mathbf{C}\right]}\end{array}$ & $\begin{array}{c}\text { product 4 } \\
{[\%]^{\mathbf{b}}}\end{array}$ & $\begin{array}{c}\text { substrate 1 } \\
{[\%]^{\mathbf{b}}}\end{array}$ & $\begin{array}{c}\text { intermediates 2+3 } \\
{[\%]^{\mathbf{b}}}\end{array}$ & $\begin{array}{c}\text { alcohol 5 } \\
{[\%]^{\mathbf{b}}}\end{array}$ \\
\hline 1 & $\mathrm{KOH}$ & 170 & 53 & 6 & 39 & 2 \\
2 & $\mathrm{NaOH}$ & 170 & 49 & $<1$ & 50 & 1 \\
3 & $\mathrm{NaOMe}$ & 170 & 50 & 1 & 48 & 2
\end{tabular}

${ }^{a}$ Conditions: $0.6 \mathrm{M} \alpha$-tetralone (1), 1.5 equiv $\mathrm{N}_{2} \mathrm{H}_{4} \cdot \mathrm{H}_{2} \mathrm{O}, 3$ equiv base, $2 \mathrm{~mL} \mathrm{MeOH}, 30 \mathrm{~min}$ at $170{ }^{\circ} \mathrm{C}, \mathrm{FO}$ temperature measurement, $10 \mathrm{~mL} \mathrm{SiC}$ vial

${ }^{\mathrm{b}}$ Determined by HPLC peak area integration at $215 \mathrm{~nm}$ 
Table S3. Reagent Stoichiometry Screeninga

\begin{tabular}{cccccccc}
\hline entry & $\begin{array}{c}\text { equiv } \\
\mathbf{N}_{\mathbf{2}} \mathbf{H}_{\mathbf{4}}\end{array}$ & $\begin{array}{c}\text { equiv } \\
\mathbf{K O H}\end{array}$ & $\begin{array}{c}\mathbf{T} \\
{\left[{ }^{\circ} \mathbf{C}\right]}\end{array}$ & $\begin{array}{c}\text { product } \\
\mathbf{4}[\mathbf{\%}]^{\mathbf{b}}\end{array}$ & $\begin{array}{c}\text { substrate } \\
\mathbf{1}[\mathbf{\%}]^{\mathbf{b}}\end{array}$ & $\begin{array}{c}\text { intermediates } \\
\mathbf{2 + 3}[\mathbf{\%}]^{\mathbf{b}}\end{array}$ & $\begin{array}{c}\text { alcohol } \\
\mathbf{5}[\boldsymbol{\%}]^{\mathbf{b}}\end{array}$ \\
\hline 1 & 3 & 3 & 170 & 59 & 8 & 30 & 3 \\
2 & 1.5 & 3 & 170 & 53 & 6 & 39 & 2 \\
3 & 1.0 & 3 & 190 & 64 & 11 & 19 & 6 \\
4 & 1.5 & 1.5 & 190 & 66 & 7 & 26 & 1 \\
5 & 1.5 & 3 & 190 & 82 & 8 & 5 & 5 \\
$6^{c}$ & 1.5 & 3 & 190 & 92 & $<1$ & 2 & 4 \\
\hline
\end{tabular}

${ }^{a}$ Conditions: $0.8 \mathrm{M} \alpha$-tetralone (1), base, $\mathrm{N}_{2} \mathrm{H}_{4} \cdot \mathrm{H}_{2} \mathrm{O}, 2 \mathrm{~mL} \mathrm{MeOH}, 30 \mathrm{~min}$, FO temperature measurement, $10 \mathrm{~mL} \mathrm{SiC}$ vessel

${ }^{\mathrm{b}}$ Determined by HPLC peak area integration at $215 \mathrm{~nm}$

${ }^{c} \mathrm{NaOH}$ was used as base 


\section{Microwave Heating Profiles}

Pressure monitoring clearly displayed a sharp rise in pressure at higher concentrations due to larger amounts of nitrogen present in the sealed vessel. Figure S1 shows a comparison of the temperature and pressure profiles for the reduction of $0.6 \mathrm{M}$ (a) and $1.4 \mathrm{M}$ (b) solutions under sealed vessel (SiC) microwave conditions.

a)
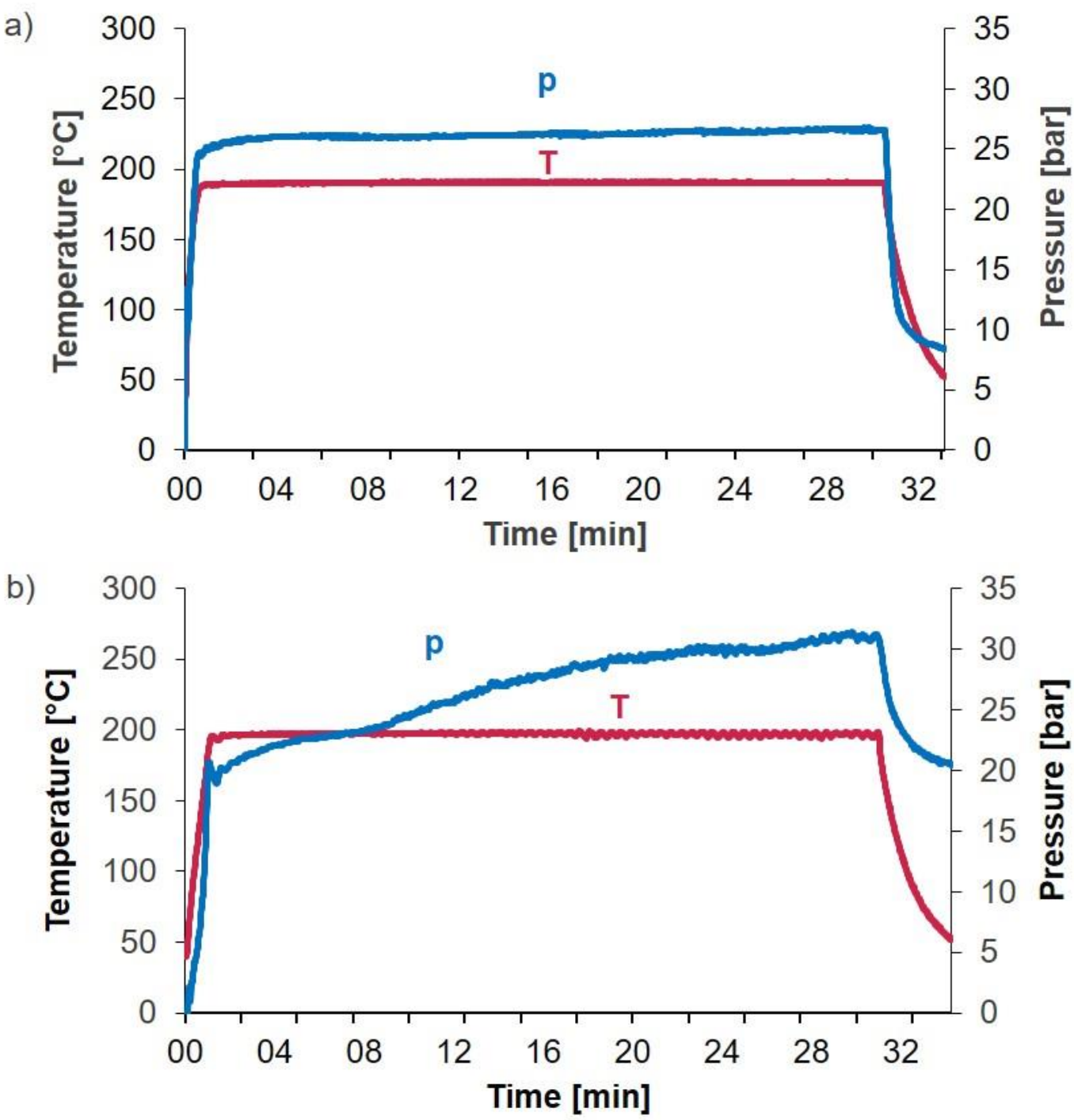

Figure S1. Internal reaction temperature $(\mathrm{T})$ and pressure (p) profiles for the Wolff-Kishner reduction of $\alpha$-tetralone (1) under microwave irradiation. a) $0.6 \mathrm{M} \alpha$-tetralone (1) in $\mathrm{MeOH}$; b) $1.4 \mathrm{M} \alpha$-tetralone (1) in $\mathrm{MeOH}$. 


\section{Continuous Flow Set-up}

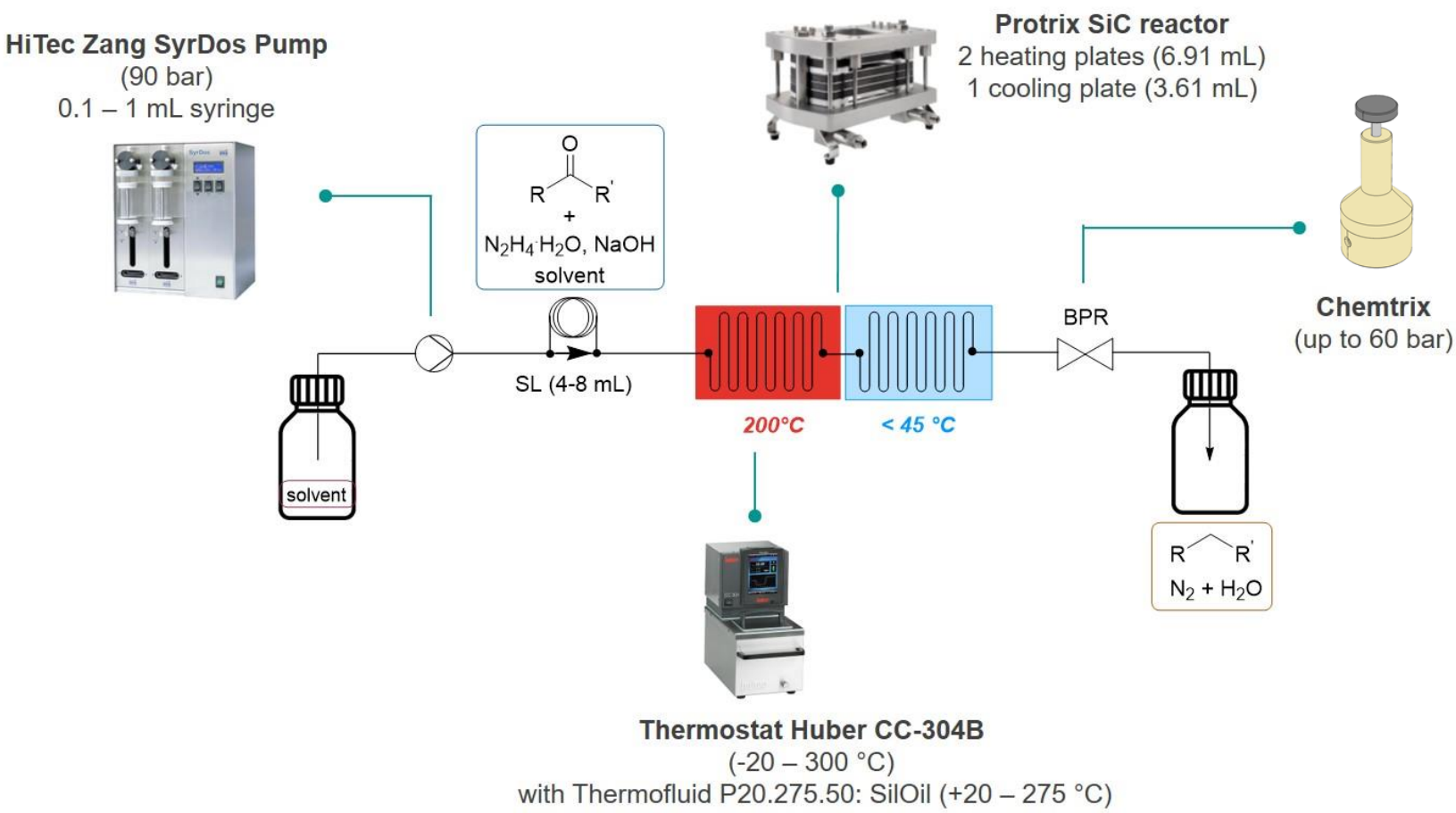

Figure S2. Continuous flow set-up (schematic).

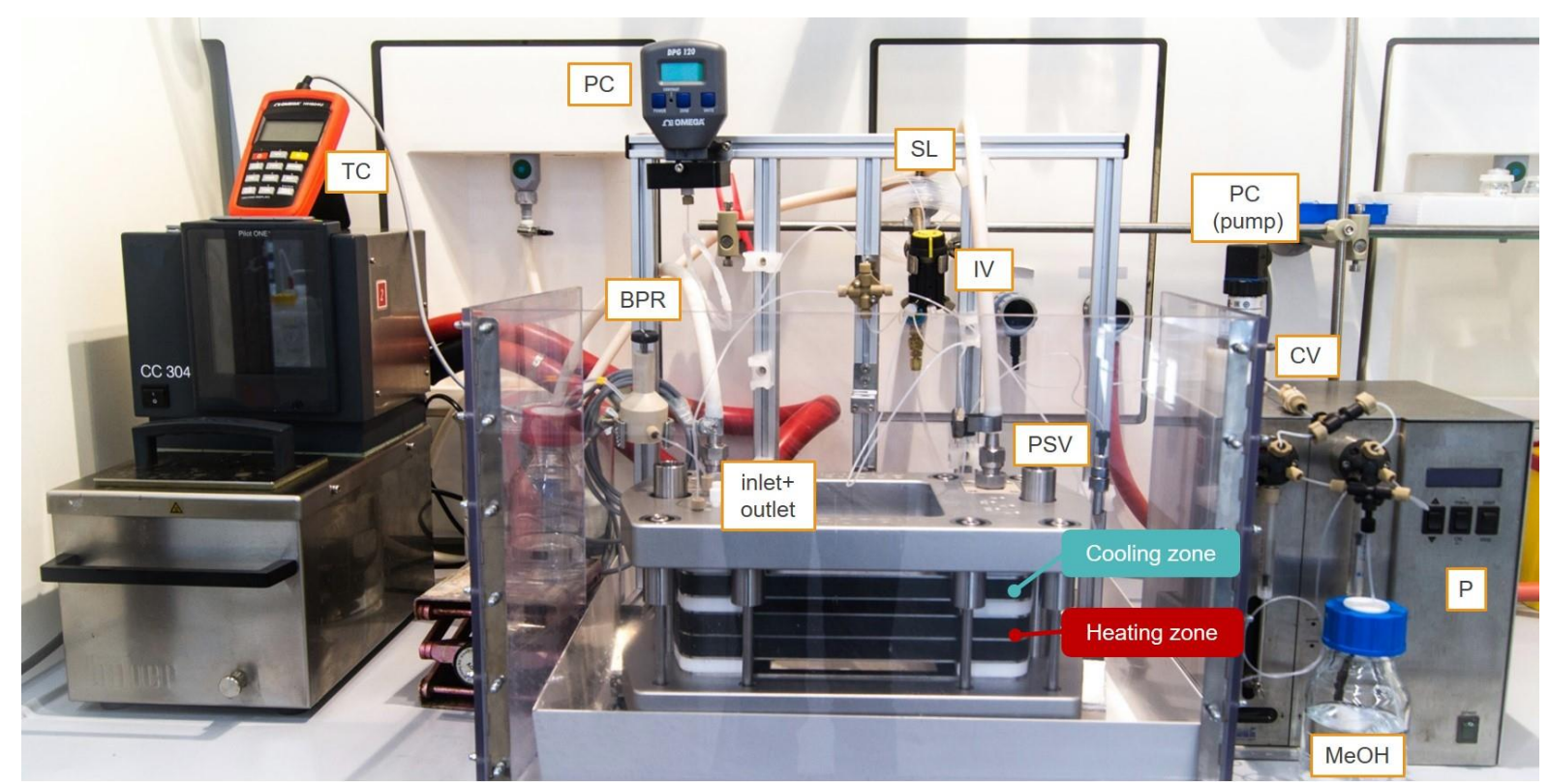

Figure S3. Image of continuous flow set-up. BPR: Back Pressure Regularor; CV: Check Valve; IV: Injection Valve, P: Pump; PC: Pressure Control, PSV: Pressure Safety Valve; TC: Temperature Control; The cooling zone of the reactor was cooled by water using an aquarium pump. 
Temperature control: Thermal regulation of the heating zone was carried out using a Huber thermostat CC304B $\left(-20-300{ }^{\circ} \mathrm{C}\right)$ filled with Thermofluid P20.275.50 (+20 - $\left.275{ }^{\circ} \mathrm{C}\right)$. Thermal regulation of the cooling zone to $40{ }^{\circ} \mathrm{C}$ was carried out with water, re-circulated using an aquarium pump. At lower temperatures, hydrazone and/or azine precipitated inside the cooling zone and at the outlet, if full conversion was not reached.

Pumps: The feed solution was pumped using HiTec Zang SyrDos (90 bar) syringe pumps with $1 \mathrm{~mL}$ syringes (0.1-1 $\left.\mathrm{mL} \mathrm{min}^{-1}\right)$ or a Knauer HPLC pump (0.001-10 $\left.\mathrm{mL} \mathrm{min}^{-1}\right)$.

Sample loop: An IDEX 6-way switching valve was used (V-450, 69 bar, IDEX), with a sample loop (made from 1/16" outer diameter, $0.8 \mathrm{~mm}$ internal diameter PFA tubing, 69 bar) installed.

Flow reactor: The Protrix flow reactor was a non-standard unit, modified to allow higher temperatures and pressures. For the heating zone, MRPX+MRPA (volume $=6.9 \mathrm{~mL}$ ) modules were used. For the cooling zone, a MRPA $(3.6 \mathrm{~mL})$ module was employed. The standard PTFE interconnector plate that creates a second thermal zone was replaced by a custom GF PEEK interconnector plate; this allowed temperatures $>150{ }^{\circ} \mathrm{C}$ and pressures $>25$ bar to be employed. The use of high temperature hydrazine monohydrate required FFKM O-rings (Chemraz 605).

Back pressure regulator: A spring type Chemtrix BPR that is adjustable up to 60 bar was employed.

General connections: PFA tubing (1/16" outer diameter, $0.8 \mathrm{~mm}$ internal diameter, $69 \mathrm{bar}$ ), with fittings (PEEK nut, P-249, IDEX) and ferrules (P-259, 93 bar, IDEX) for high pressure was used. 


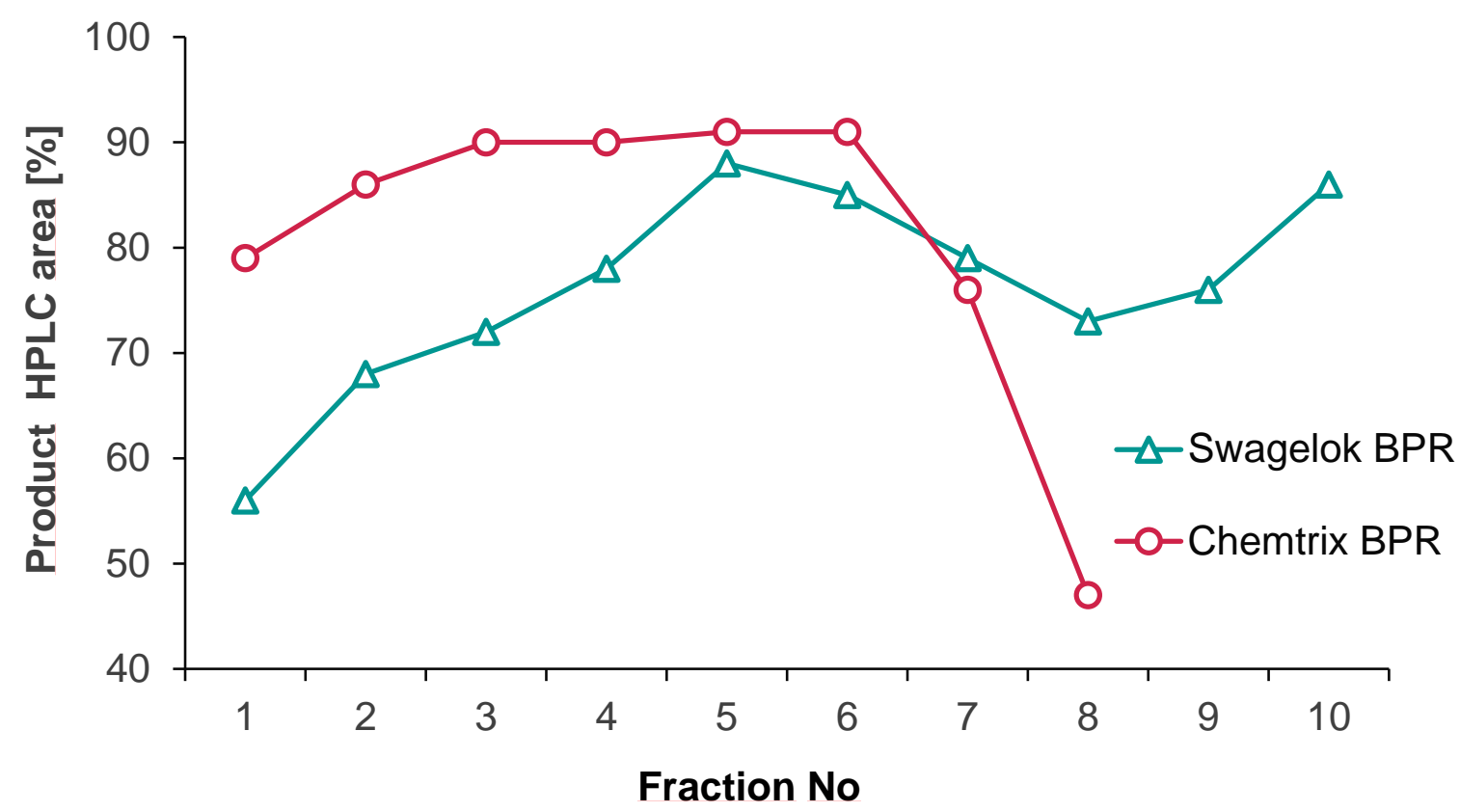

Figure S4. Comparison of product distribution using different back pressure regulators (BPRs). Conditions: $0.8 \mathrm{M} \alpha$-tetralone in carbitol, 3.0 equiv $\mathrm{KOH}, 1.5$ equiv $\mathrm{N}_{2} \mathrm{H}_{4} \cdot \mathrm{H}_{2} \mathrm{O}$, $200{ }^{\circ} \mathrm{C}, 15 \mathrm{bar}, 0.38 \mathrm{~mL} / \mathrm{min}, 4 \mathrm{~mL}$ sample loop. Fraction volume: $\sim 1 \mathrm{~mL}$

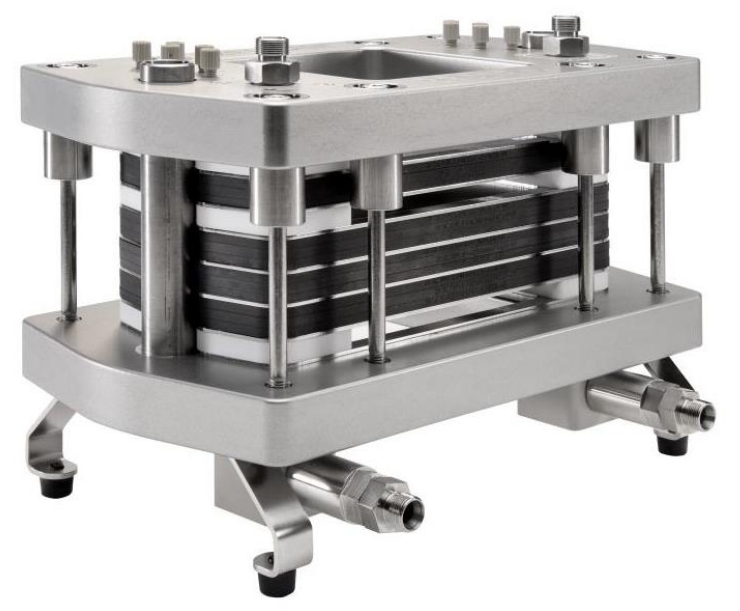

Figure S5. Modular Protrix reactor with flexible reaction volumes $(1-13.5 \mathrm{~mL})$. 

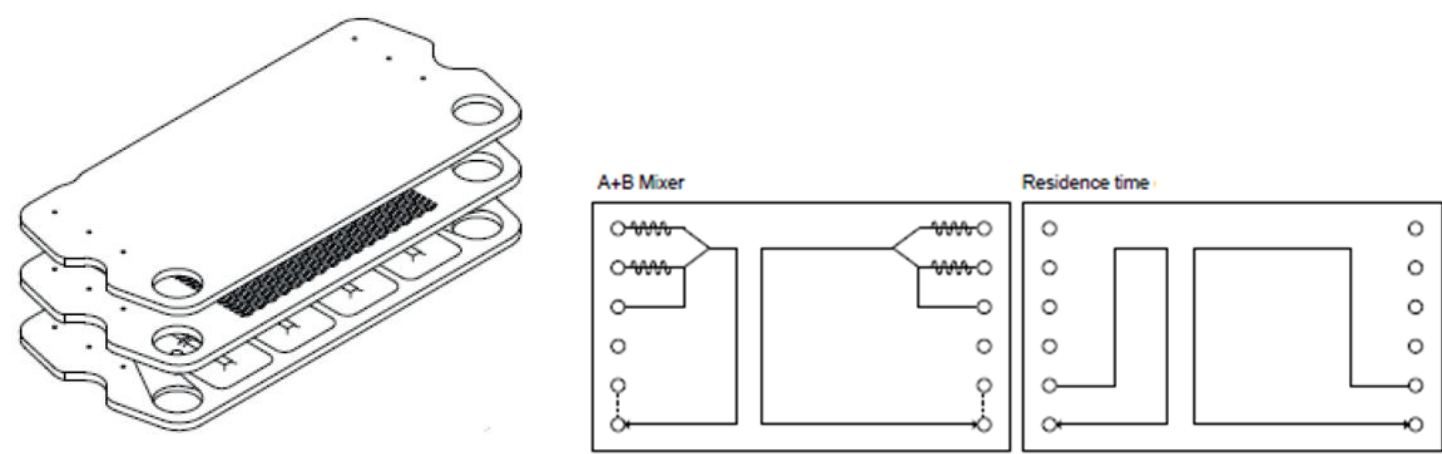

Figure S6. Left: exploded view of a $3 \mathrm{M}^{\mathrm{TM}} \mathrm{SiC}$ Protrix module - showing process and service channel arrangement. NOTE: $\mathrm{SiC}$ reactor modules are diffusion bonded and cannot be opened. Right: Schematic of the zig-zag meso-channel layouts for the process fluid. Channel dimensions: 1 x $1 \mathrm{~mm}$ (pre-heat and mixer zone), 1.4 x $1.4 \mathrm{~mm}$ (residence channel); two independent reaction volumes are present per $3 \mathrm{M}^{\mathrm{TM}} \mathrm{SiC}$ module.

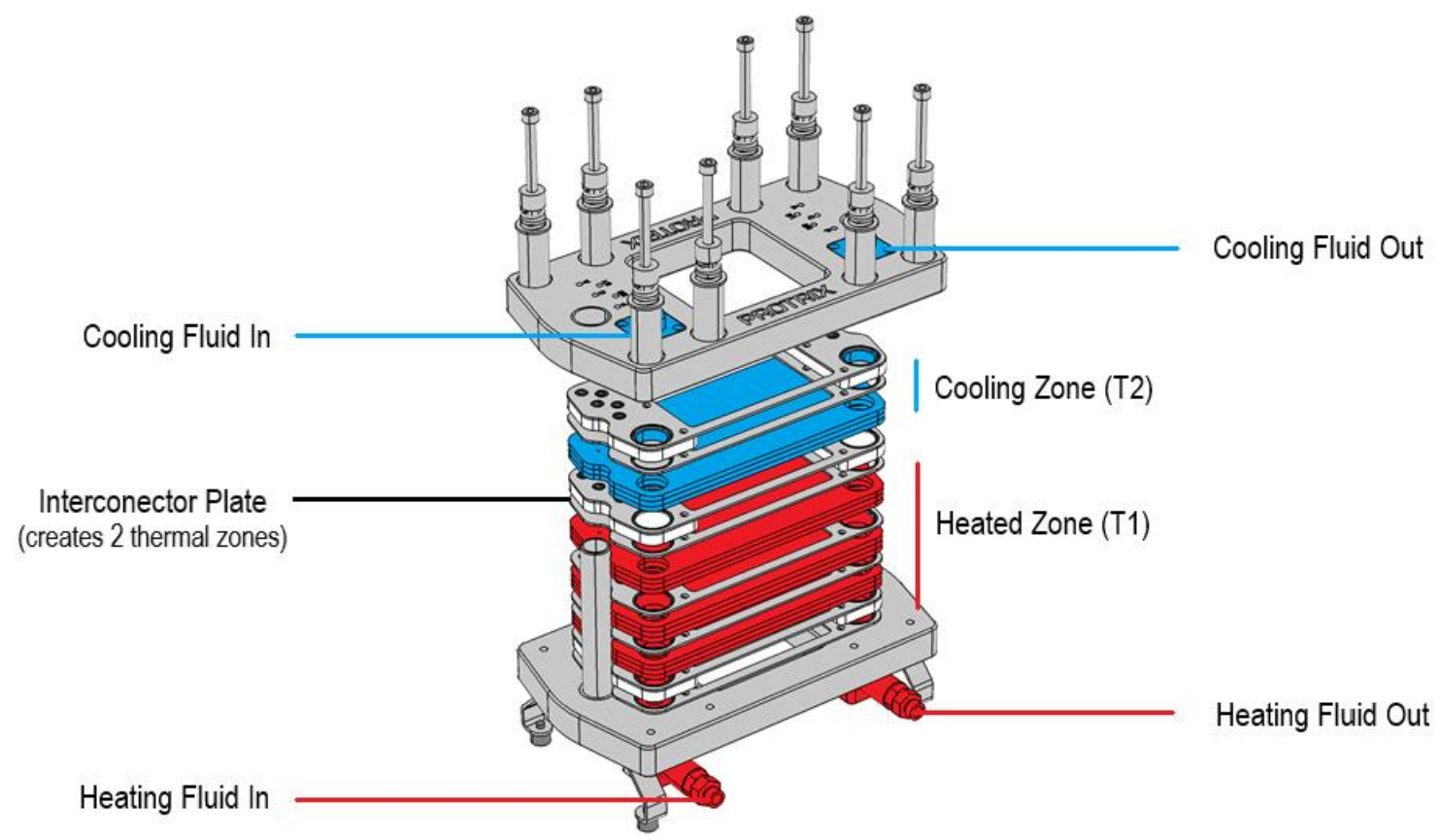

Figure S7. Exploded view of a Protrix flow reactor with two temperature zones separated via an interconnector plate (commercial: PTFE plate; for this work: customized GF PEEK plate (non-wetted)). The process fluid can be cooled down to ambient temperature before the outlet. 


\section{Substrates Unsuitable for high-T/p Conditions using MeOH}

Table S4. Substrates with Poor Performance in the Wolff-Kishner Reduction ${ }^{\text {a }}$

product
$[\%]^{\mathbf{b}}$

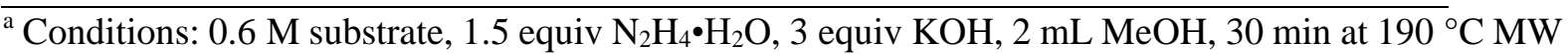
heating, IR temperature measurement, $10 \mathrm{~mL}$ Pyrex vial

${ }^{\mathrm{b}}$ Determined by HPLC peak area integration

${ }^{c}$ Dehalogenation products were confirmed by LC-MS and GC-MS

${ }^{\mathrm{d}}$ Substrate is consumed but no products related to the Wolff-Kishner reaction could be detected

${ }^{\mathrm{e}}$ The substrate is only stable up to $150{ }^{\circ} \mathrm{C}$ under those conditions, however no full conversion could be achieved. At higher temperatures, full conversion was achieved, but also unidentified side products were detected. 


\section{Stability Tests of the Feed Solution}

Studies at different temperatures over a period of $30 \mathrm{~h}$ have shown that reaction mixtures in $\mathrm{MeOH}$ stayed homogenous for the entire period, both at room temperature and at $4{ }^{\circ} \mathrm{C}$ without significant formation of side products or decomposition. The feed solution was much more stable in the absence of hydrazine. Decreasing the storage temperature to $4{ }^{\circ} \mathrm{C}$ minimized the formation of hydrazone 2 and azine 3 in $\mathrm{MeOH}$. It has to be noted, that the presence of hydrazone $\mathbf{2}$ and azine 3 in the feed solution did not have any detrimental effect on the reaction profile. This was proven by subjecting a freshly prepared feed solution and a $30 \mathrm{~h}$ old feed solution to microwave irradiation, obtaining the same purity profile (97\% product $4,3 \%$ alcohol 5).

Stability in MeOH. To a $10 \mathrm{~mL}$ Pyrex vial equipped with a magnetic stirring bar, were added $\alpha$-tetralone ( $319 \mu \mathrm{L}, 2.4 \mathrm{mmol}), \mathrm{NaOH}$ (288 mg, $7.2 \mathrm{mmol}, 3.0$ equiv), $\mathrm{N}_{2} \mathrm{H}_{4} \cdot \mathrm{H}_{2} \mathrm{O}(175 \mu \mathrm{L}$, $3.6 \mathrm{mmol}, 1.5$ equiv) and $2.0 \mathrm{~mL} \mathrm{MeOH}$. The vial was sealed with a crimp top cap and stirred for $30 \mathrm{~h}$ at $4{ }^{\circ} \mathrm{C}$ and at $\mathrm{rt}$, respectively. Samples were withdrawn regularly for HPLC analysis.
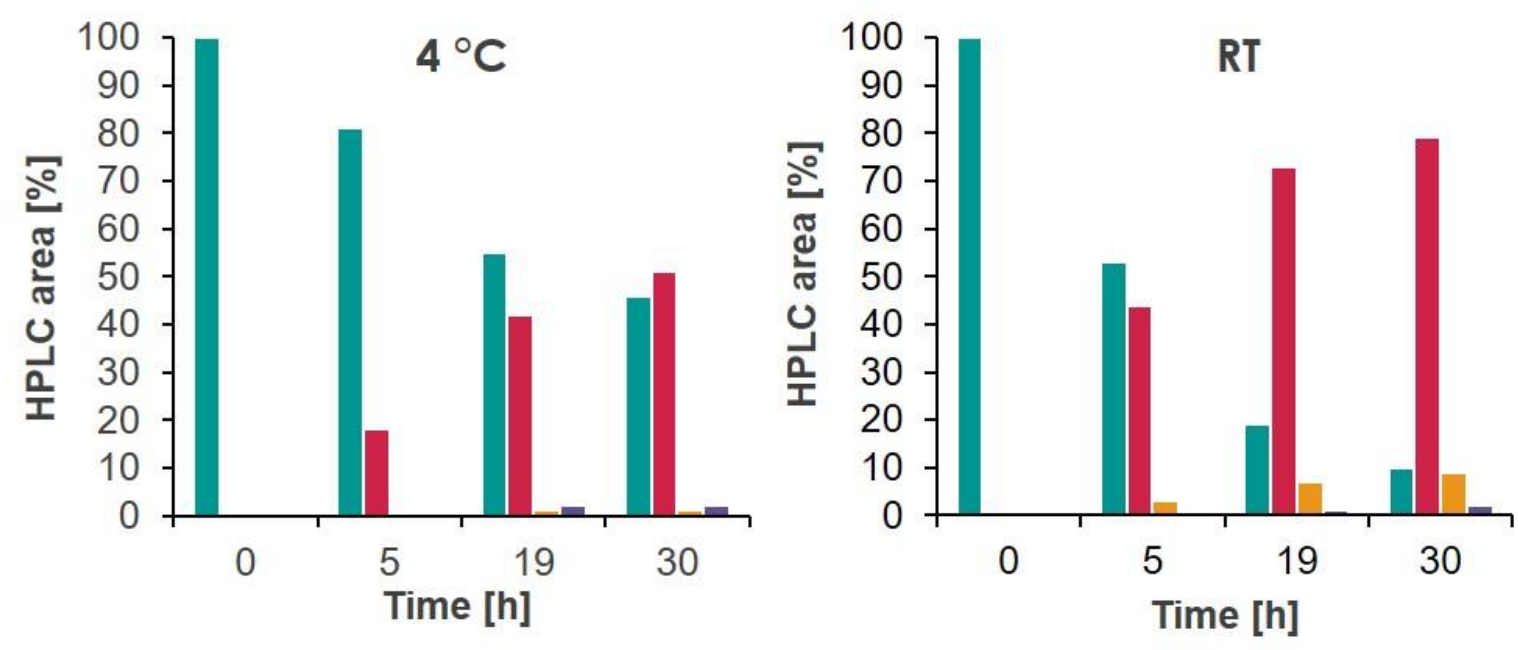

Substrate $\quad$ Hydrazone $\|$ Azine Alcohol

Figure S8. HPLC monitoring $(215 \mathrm{~nm})$ of the feed solution in $\mathrm{MeOH}$. 


\section{Quantification of Residual Hydrazine}

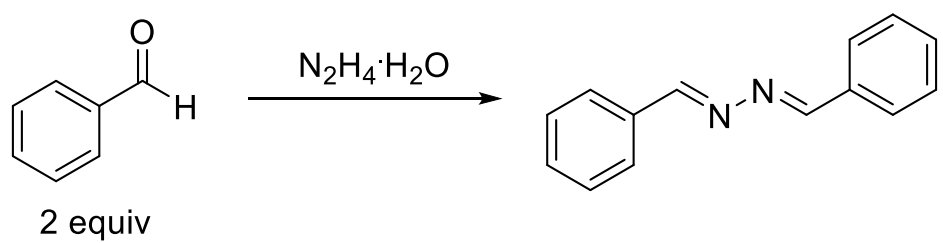

Scheme S1. Reaction of benzaldehyde with hydrazine.

Benzaldehyde was used as a trapping agent in order to determine the amount of residual hydrazine after the reaction has proceeded (Scheme S1). Therefore, $1.0 \mathrm{mmol}$ benzaldehyde (108 mg) was added to $500 \mu \mathrm{L}$ of crude reaction mixture and stirred for $30 \mathrm{~min}$ at RT. An aliquot was taken, and the amount of unreacted benzaldehyde was determined by calibrated UPLC. The quantity of consumed benzaldehyde correlates to the amount of residual hydrazine. The amount of residual hydrazine was calculated based on the assumption that 1 equiv hydrazine is consumed in the Wolff-Kishner reaction. Theoretically, 0.5 equiv of hydrazine should be present after the reaction has proceeded to completion, since 1.5 equiv of hydrazine was used. 
7. ${ }^{1} \mathrm{H}-\mathrm{NMR}(300 \mathrm{MHz})$ and ${ }^{13} \mathrm{C}-\mathrm{NMR}(75 \mathrm{MHz})$ Spectra in $\mathrm{CDCl}_{3}$
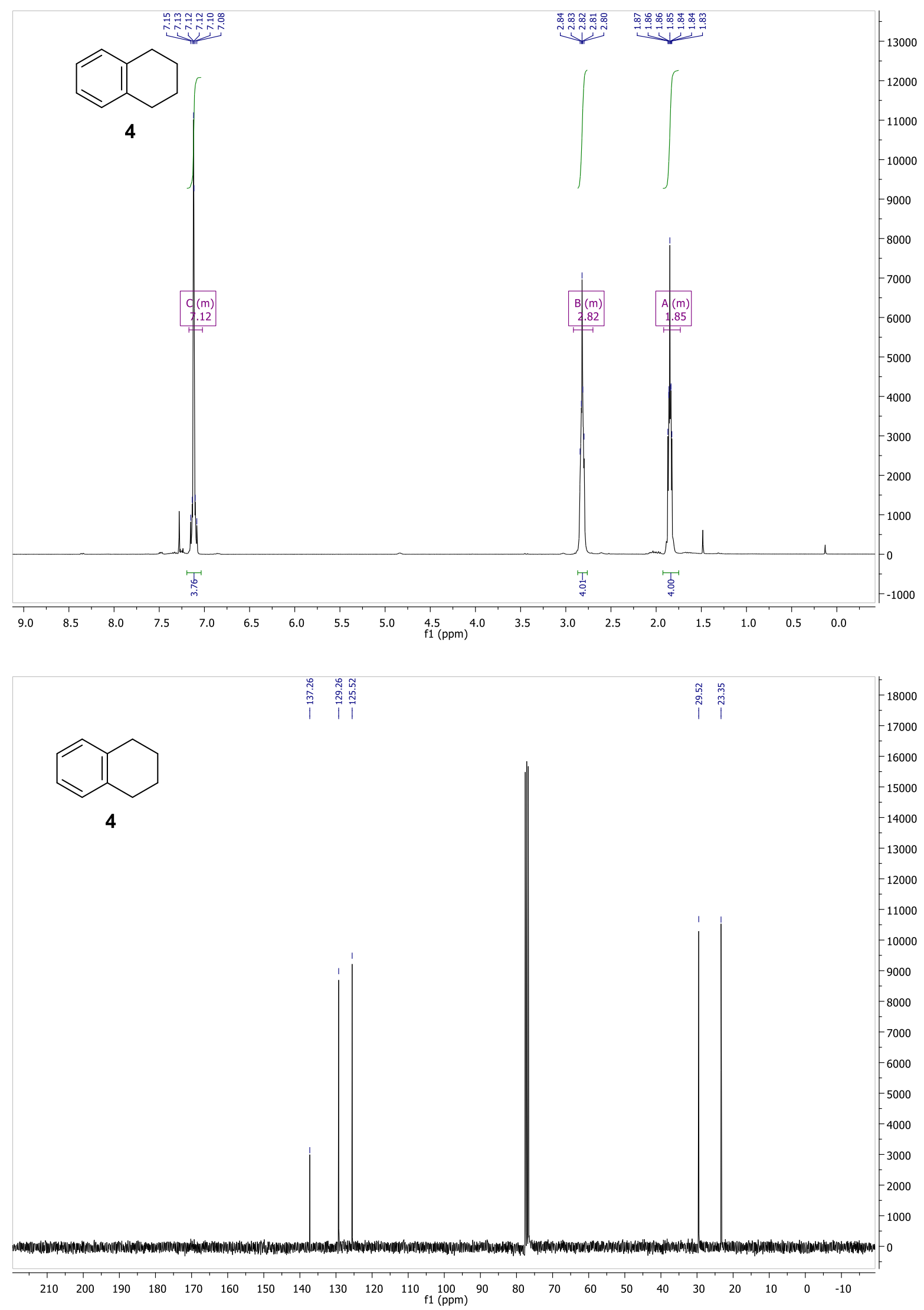

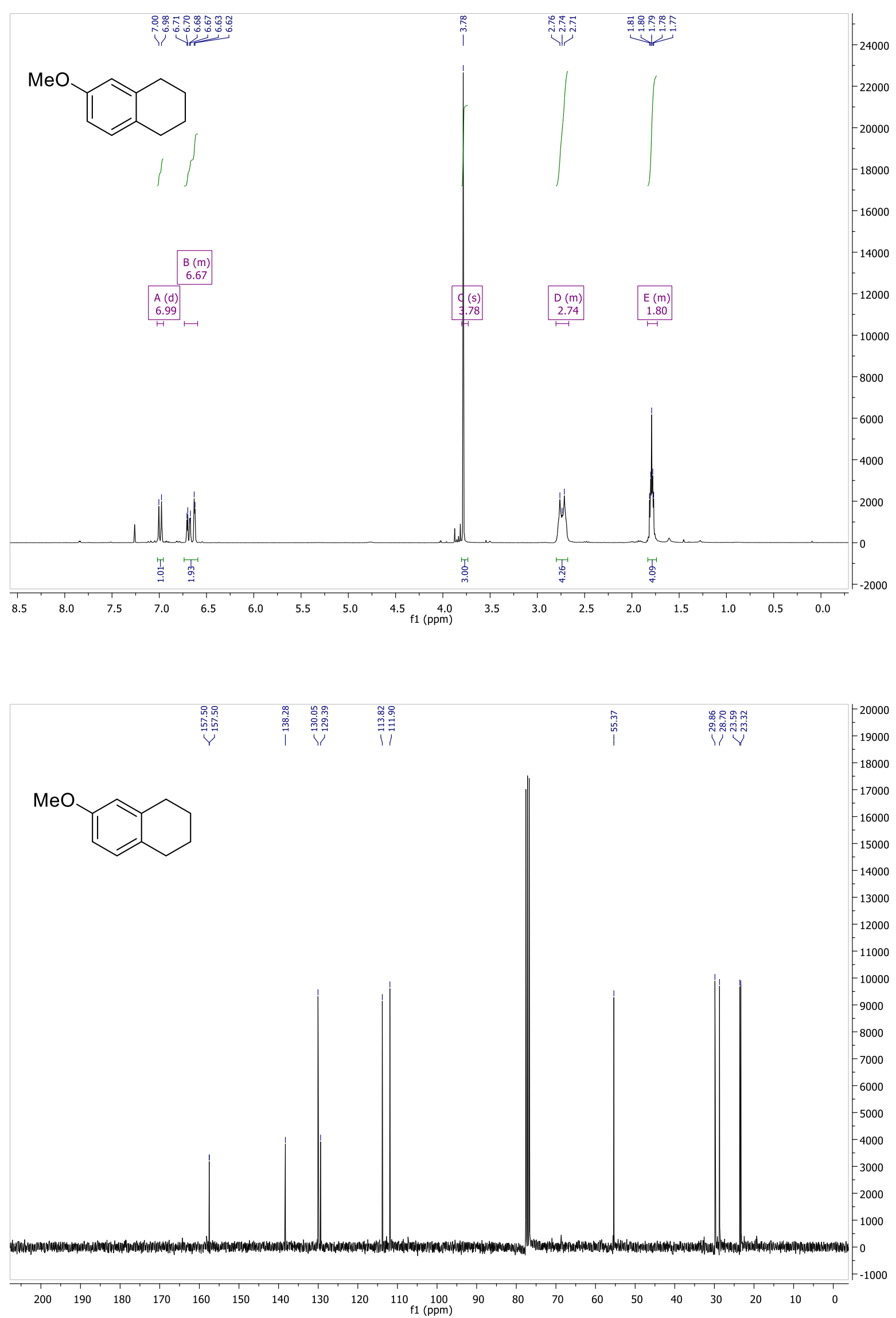

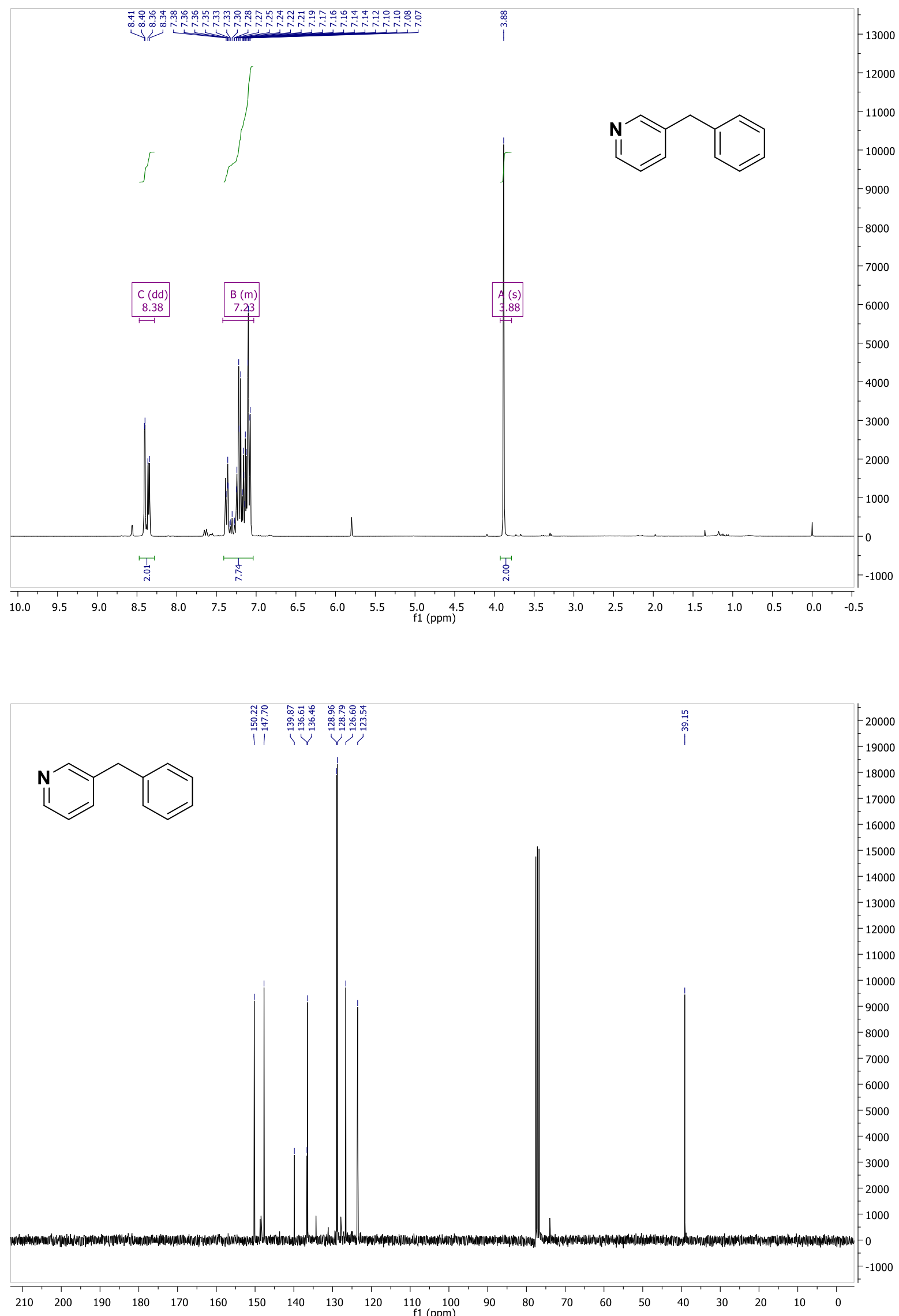

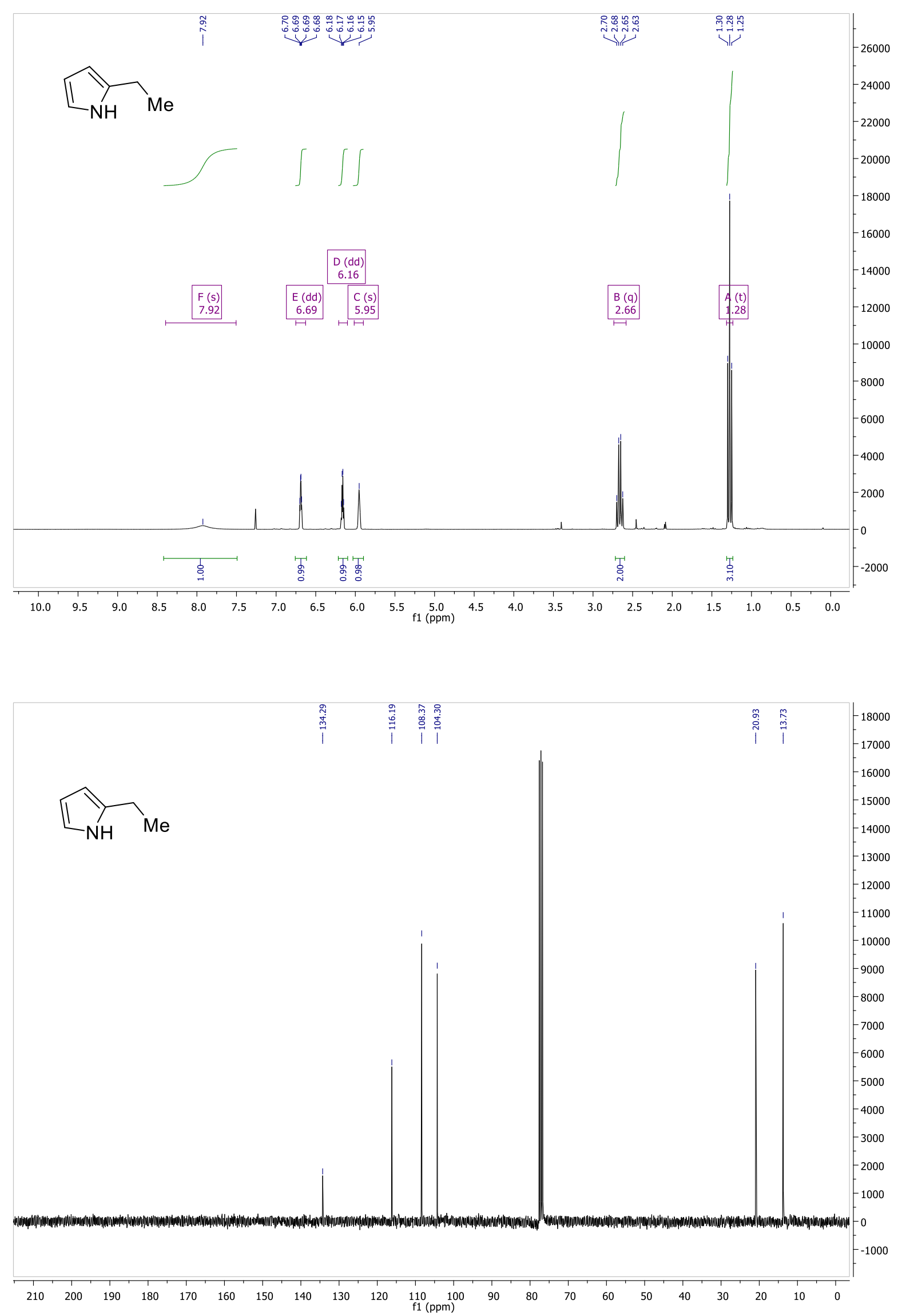
S16
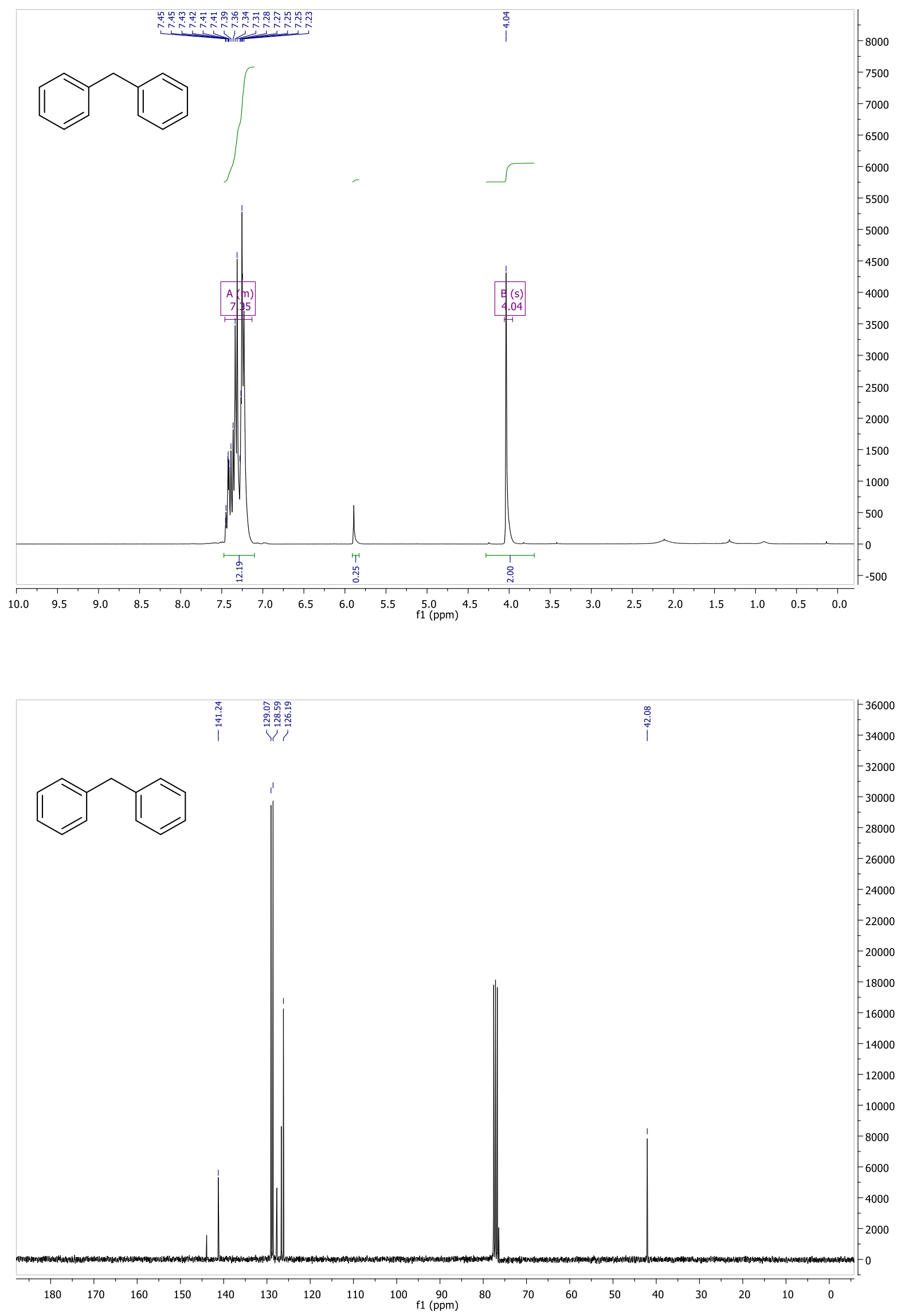

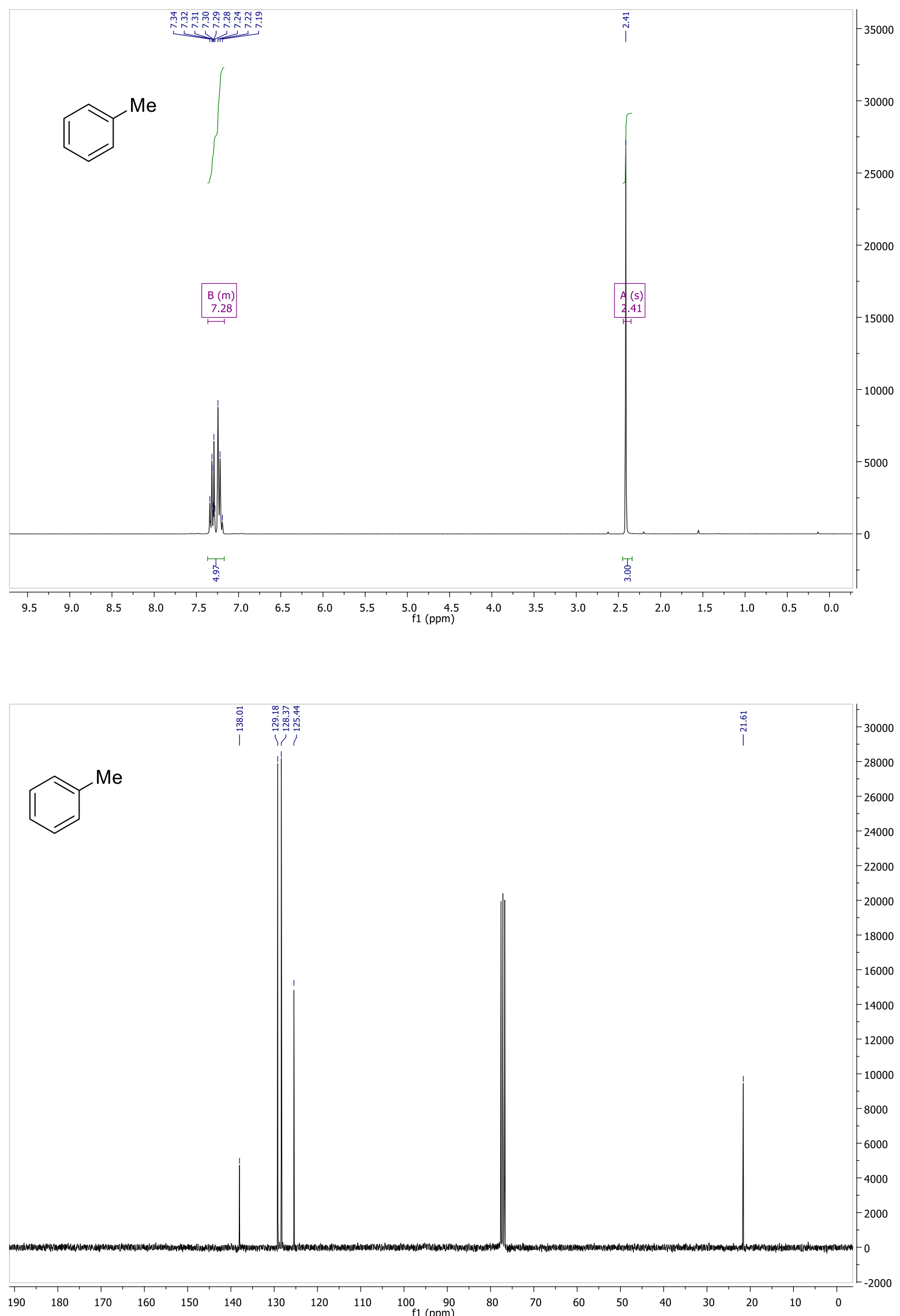

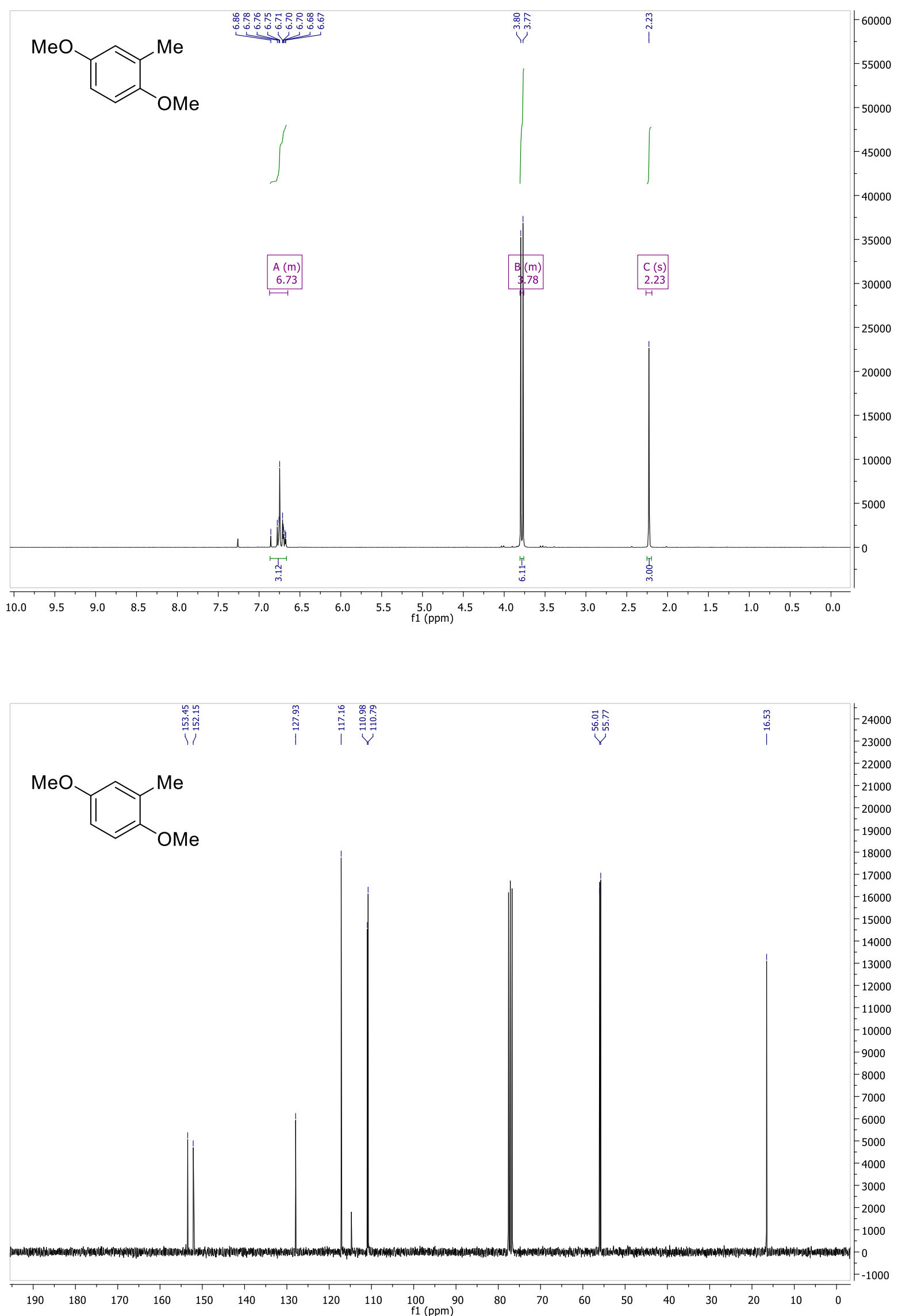

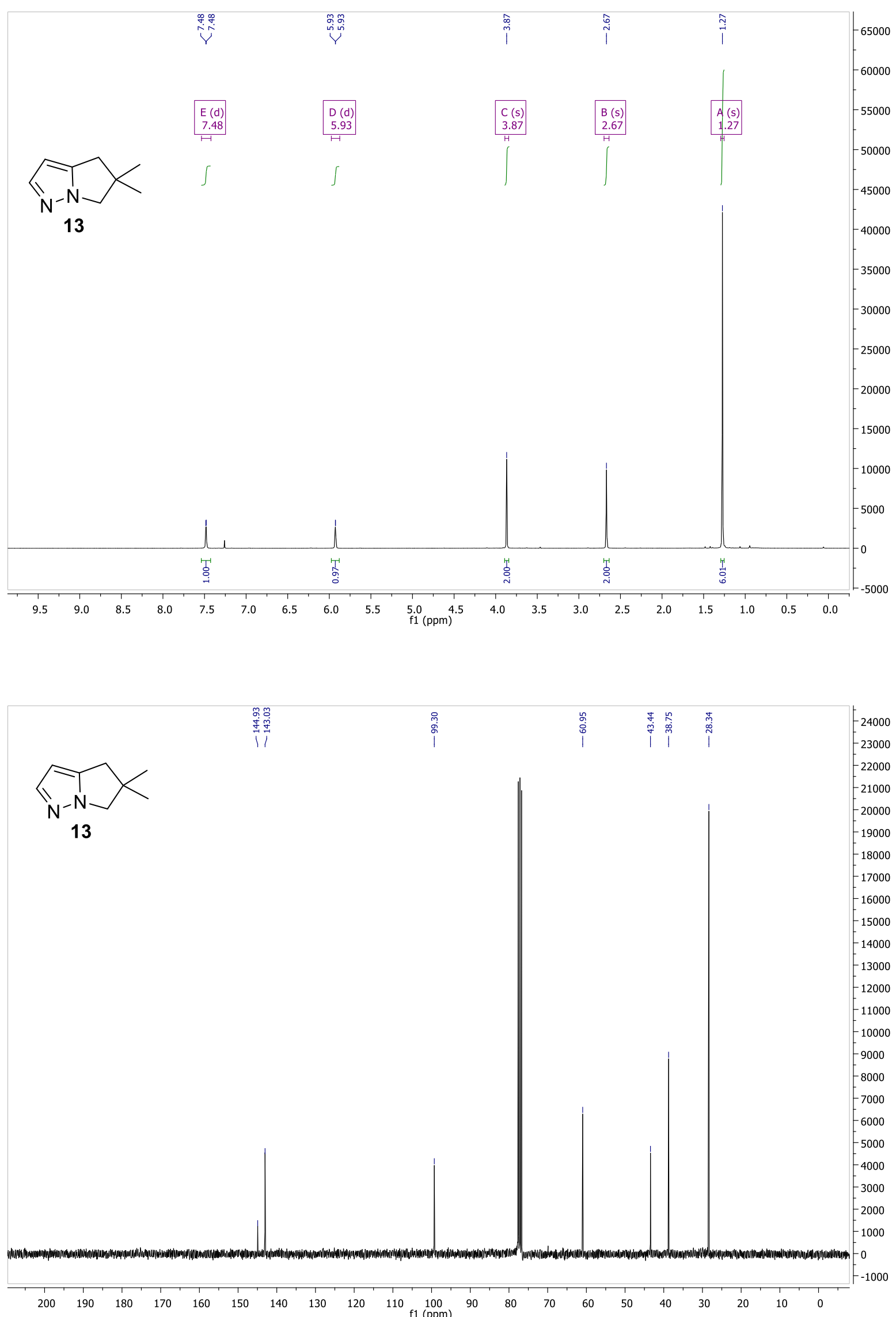